DOI:10.2478/rrlm-2019-0015

\title{
Antibacterial activity of selected snake venoms on pathogenic bacterial strains
}

\author{
Francisc Andrei Boda ${ }^{1}$, Anca Mare ${ }^{2 *}$, Zoltán István Szabó ${ }^{3}$, Lavinia Berta ${ }^{1}$, \\ Augustin Curticapean ${ }^{1}$, Maria Dogaru ${ }^{4}$, Adrian Man ${ }^{2}$ \\ 1. Department of General and Inorganic Chemistry, Faculty of Pharmacy, University of Medicine, \\ Pharmacy, Sciences and Technology of Târgu Mureș, Romania \\ 2. Department of Microbiology, Faculty of Medicine, University of Medicine, Pharmacy, Sciences and \\ Technology of Târgu Mureș, Romania \\ 3. Department of Drugs Industry and Pharmaceutical Management, Faculty of Pharmacy, University \\ of Medicine, Pharmacy, Sciences and Technology of Târgu Mureș, Romania \\ 4. Department of Pharmacology and Clinical Pharmacy, Faculty of Pharmacy, University of Medicine, \\ Pharmacy, Sciences and Technology of Târgu Mureș, Romania
}

\begin{abstract}
Snake venoms are aqueous solutions containing peptides and proteins with various biochemical, physiological, and pathophysiological effects. Several snake venom components are used as lead molecules in the development of new active substances for the treatment of cardiovascular diseases, clotting disorders, cancer or pain.

Antibacterial activity has also been attributed to snake venoms and proteins isolated from snake venoms. This study provides information regarding the antibacterial activity of venoms obtained from various snake species from the Elapidae and Viperidae families. Minimum inhibitory and bactericidal concentrations of snake venoms were determined for three Gram-positive (Enterococcus faecalis ATCC 29212, Staphylococcus aureus ATCC 29213, and Methicillin-resistant Staphylococcus aureus ATCC 43300) and three Gram-negative (Escherichia coli ATCC 25922, Klebsiella pneumoniae ATCC 13883, and Pseudomonas aeruginosa ATCC 27853) pathogenic bacteria. The observed effects were correlated with the protein content of each venom, determined using SDS-PAGE analysis and comparison with data available in the literature. Our findings represent a starting point for the selection of snake venoms containing components with potential use as lead molecules in the development of new antibacterial agents, targeting multidrug resistant bacterial strains.
\end{abstract}

Keywords: snake venom; antibacterial activity; toxins; inhibitory concentration; bactericidal concentration Received: 24 $4^{\text {th }}$ September 2018; Accepted: $7^{\text {th }}$ February 2019; Published: $11^{\text {th }}$ February 2019

\footnotetext{
*Corresponding author: Anca Mare, Department of Microbiology, Faculty of Medicine, University of Medicine, Pharmacy, Sciences and Technology of Târgu Mureș, Romania. E-mail: mareanca@gmail.com
} 


\section{Introduction}

Antibiotic resistance developed by numerous bacterial strains is the main cause for the decrease in the effectiveness of antibiotics and the treatment of infectious diseases caused by multidrug resistant bacteria represents a significant clinical problem $(1,2)$. In this context, the discovery of new antimicrobial agents is crucial, and the search for new compounds has led to the exploration of various natural sources, such as plant extracts (3-5), bee venom (6), spider venom (7) or snake venom (8).

Snake venoms are aqueous solutions containing peptides and proteins that affect the nervous, cardiovascular, and neuromuscular systems (9). Several snake venom components are used as lead molecules in the development of new active substances for the treatment of cardiovascular diseases $(10,11)$, clotting disorders $(12,13)$, cancer $(14,15)$, or pain $(16)$. Snake venoms and individual components isolated from snake venoms demonstrated antibacterial activity against several Gram-positive and Gram-negative bacteria (17-19). Based on the results of these experiments, the antibacterial activity of snake venoms has been attributed mainly to their content in phospholipases, metalloproteinases, and L-amino acid oxidases (8).

Snake venom phospholipases $\mathrm{A}_{2}$ (sv-PLA $)$ are enzymes capable of hydrolysing phospholipids, but express additional biological activities, such as neurotoxicity, cardiotoxicity, and myotoxicity (20,21). Analgesic (16), antitumoral (22), and antibacterial effects (23) have also been attributed to sv-PLA 2 s. Studies focused on the antibacterial activity of sv-PLA $\mathrm{S}_{2}$ s have demonstrated that several of these proteins are active on both Gram-positive and Gram-negative bacteria, with a more pronounced effect on Gram-positive strains $(19,24)$. The preferential activity on Gram-positive bacteria might be explained by the positive charge of the sv-PLA 2 molecules, which potentiates the binding of the proteins to the anionic surface of the cell wall, leading to the enzymatic degradation of its constituent phospholipids $(8,23)$.

Snake venom metalloproteinases (SVMP) are zinc-dependent enzymes that are able to cause haemorrhages, coagulopathies, and myonecrosis. SVMPs also inhibit platelet aggregation and induce inflammatory responses (25). SVMPs present proteolytic activity and are capable of modulating the cell-cell and cell-matrix adhesion processes, which might be directly linked to their antibacterial activity (26). Studies regarding the antibacterial activity of SVMPs found that these proteins show inhibitory activities against several Gram-positive and Gram-negative bacterial strains, with a more pronounced activity on Gram-positive strains. The antibacterial effect of SVMPs is partially related to bacterial anionic site recognition and degradation of phospholipid membranes $(8,26)$.

Snake venom L-amino acid oxidases (svLAAO) are FAD-binding glycoproteins that present cytotoxic, apoptotic, haemorrhagic, and antibacterial activity (27). The antibacterial activity of sv-LAAOs is attributed to their catalytic activity during amino acid oxidations. These processes lead to the generation of hydrogen peroxide, a bactericidal molecule with activity on both Gram-positive and Gram-negative strains $(8,28)$.

In the study presented here, we hypothesized that venoms originating from various snake species present different antibacterial activity depending on their protein composition. The main objective of the study was to determine the minimum inhibitory and minimum bactericidal concentrations of lyophilized snake venoms and to correlate our findings with the protein composition of the venoms determined using sodium dodecyl sulfate-polyacrylamide gel electrophoresis (SDS-PAGE). 


\section{Material and methods}

\section{Snake venoms}

Lyophilized snake venoms were obtained from commercial sources (Latoxan S.A.S., France). Stock solutions were prepared by dissolving the lyophilized snake venoms in sterile distilled water at a concentration of $8000 \mu \mathrm{g} / \mathrm{mL}$ and used immediately. Venoms used in the present study originated from snakes of the Elapidae and Viperidae family and included the following species:

- Elapidae: Acanthophis praelongus (Product ID: L1359), Dendroaspis angusticeps (L1307), Naja atra (L1322), and Naja kaouthia (L1323)

- Viperidae: Agkistrodon piscivorus leucostoma (L1205), Agkistrodon piscivorus piscivorus (L1206), Bitis gabonica (L1104A), Crotalus atrox (L1216), Crotalus polystictus (L1292), Daboia siamensis (L1139A), and Vipera latastei gaditana (L1153).

\section{Bacterial strains}

Six control strains were obtained from the bacterial collection of the Department of Microbiology, the University of Medicine, Pharmacy, Science, and Technology of Târgu Mureș, Romania. Bacterial strains used in the present study include Enterococcus faecalis (ATCC 29212), Staphylococcus aureus (ATCC 29213), Methicillin-resistant Staphylococcus aureus (MRSA) (ATCC 43300), Escherichia coli (ATCC 25922), Klebsiella pneumoniae (ATCC 13883), and Pseudomonas aeruginosa (ATCC 27853). The first three strains are representative for Gram-positive cocci, while the last three for Gram-negative rods: glucose-fermentative as well as non-glucose-fermentative rods. The strains were revitalized 48 hours prior to the experiment on blood-agar and incubated overnight at $37^{\circ} \mathrm{C}$, subcultured and checked for their purity. Isolated colonies were then used for inoculum preparation.

\section{Antibacterial activity of snake venoms}

The antibacterial activity of snake venoms was assessed using the microdilution method that allows the determination of minimum inhibitory concentrations (MIC) on sterile 96-well polystyrene round bottom micro-well plates. The method is based on CLSI 2015 standard methodology (document M07A10) (29).

For the testing of each bacterial strain, two 96well plate sets were used (one plate serving for the testing of six venoms, the second for the testing of five venoms). On the first well of each corresponding row, $200 \mu \mathrm{L}$ of crude venom stock solutions were loaded. One hundred microliters of each venom was subsequently mixed with $100 \mu \mathrm{L}$ sterile distilled water in the remaining wells of the corresponding row, thus obtaining successive binary dilutions. Standard bacterial inoculums, each containing approximately $2 \cdot 10^{5}$ colony-forming units (CFU) per $\mathrm{mL}$, were prepared by mixing $10 \mu \mathrm{L}$ of 0.5 McFarland bacterial suspension in sterile saline with $9990 \mu \mathrm{L}$ Muller-Hinton broth (Oxoid Limited, UK), 2x concentrated. One hundred microliters of bacterial inoculum were pipetted over the $100 \mu \mathrm{L}$ of venom solutions in each of the two corresponding plate sets. Thus, the final concentrations of the venoms in wells $1-12$ of the testing plates were: 4000, 2000, 1000, 500, 250, 125, 62.5, $31.25,15.62,7.81,3.90$ and $1.95 \mu \mathrm{g} / \mathrm{mL}$, respectively, while the bacterial concentration was approximately $2 \cdot 10^{4} \mathrm{CFU} /$ well. Each plate contained two growth control wells in the last row: positive control (bacterial inoculum and water) and negative control (Muller-Hinton broth and water). All plates were incubated overnight at 35 $\pm 1^{\circ} \mathrm{C}$. The MIC was interpreted as the venom concentration in the last well of each row that did not present visible growth.

The minimum bactericidal concentration (MBC) was assessed from the last three wells that did not show bacterial growth, including the MIC one. For this purpose, $2 \mu \mathrm{L}$ solution from each well 
was spot-inoculated on Columbia-blood-agar medium (Oxoid Limited, UK) and incubated overnight at $37^{\circ} \mathrm{C}$. The $\mathrm{MBC}$ was interpreted as the lowest venom concentration that did not allow colony growth, equal with or higher than the MIC.

\section{SDS-PAGE analysis of snake venoms}

Samples taken from the stock solutions of each venom were prepared for SDS-PAGE analysis according to the method described by Laemmli (30). Proteins were separated on $10 \%$ SDS gels, run under $100 \mathrm{~V}$ voltage for 3 hours using a PowerPac HC High-Current Power Supply (Bio-Rad Laboratories, USA). Pageruler Plus prestained protein ladder, 10 to $250 \mathrm{kDa}$ (Thermo Fisher Scientific, USA) was used as a molecular marker. Gel electrophoresis was followed by protein blotting, performed using an Immun-Blot PVDF membrane (Bio-Rad Laboratories, USA). Blotting conditions were as follows: $100 \mathrm{~V}$ for 1 hour, using a PowerPac HC High-Current Power Supply (Bio-Rad Laboratories, USA). Bands obtained following protein blotting were visualized using Ponceau S stain (VWR Life Sciences, USA). Stained membranes were photographed using a ChemiDoc XRS+ System (Bio-Rad Laboratories, USA) and the obtained images were optimised and analysed using Image Lab Software version 5.2.1. (Bio-Rad Laboratories, USA).

\section{Results}

Qualitative and quantitative composition of snake venoms varies greatly between different species. Thus, it is expected that the effects of snake venoms on different organisms can show tremendous differences. The results of the antibacterial activity of different snake venoms are summarized in Table 1.

Representative composed images showing the effect of Naja atra (Elapidae) and Agkistrodon piscivorus leucostoma (Viperidae) venoms on different bacterial strains are presented in Figure 1 and a representative image showing the effect of all tested snake venoms on $S$. aureus is presented in Figure 2.

As it can be observed, the effects of venoms obtained from species of the two different families can clearly be distinguished. Elapid venoms displayed reduced or no antibacterial activity against all tested strains, with the least effective venom being the one obtained from Dendroaspis angusticeps, showing no antibacterial activity at the concentration range used. All other elapid venoms had MIC and MBC values equal or above $2000 \mu \mathrm{g} / \mathrm{mL}$. As a comparison, viperid venoms, with the exception of the venom obtained from Vipera latastei gaditana, displayed for all susceptible bacterial strains MIC and $\mathrm{MBC}$ values equal or below $500 \mu \mathrm{g} / \mathrm{mL}$.

Viperid venoms showed not only lower MIC and MBC values, but also displayed a higher inter-species variability for the determined MIC and MBC values. Venoms obtained from Bitis gabonica and Crotalus polystictus had the highest MIC values in the Viperidae family, regardless of the pathogen involved. On the other hand, promising results were found for the venoms obtained from Daboia siamensis on Gram-positive S. aureus and Agkistrodon piscivorus leucostoma on Gram-negative $K$. pneumoniae, both with MIC and MBC values of $62.5 \mu \mathrm{g} / \mathrm{mL}$. Differences in the antibacterial activities of the obtained venoms could also be observed for the two Crotalus species tested, with MIC and MBC of $125 \mu \mathrm{g} / \mathrm{mL}$ for Crotalus atrox and $500 \mu \mathrm{g} / \mathrm{mL}$ for Crotalus polystictus on susceptible species.

E. faecalis and E. coli strains were resistant to all tested venoms, while $P$. aeruginosa was susceptible only to the venoms obtained from the two Agkistrodon species and only at high concentrations (MIC and MBC of $4000 \mu \mathrm{g} / \mathrm{mL}$ ).

SDS-PAGE analysis was performed separately 
Table 1. Minimum inhibitory and minimum bactericidal concentration of different snake venoms, against Gram-positive and Gram-negative bacteria determined using the microdilution method.

(Ef-Enterococcus faecalis; Sa-Staphylococcus aureus; MRSA-Methicillin-resistant Staphylococcus aureus; Ec-Escherichia coli; Kp-Klebsiella pneumoniae; Pa-Pseudomonas aeruginosa).

\begin{tabular}{|c|c|c|c|c|c|c|c|c|c|c|c|c|c|}
\hline \multirow{3}{*}{$\begin{array}{l}\text { Snake species } \\
\text { Scientific name }\end{array}$} & \multirow{3}{*}{$\begin{array}{c}\text { Common } \\
\text { name }\end{array}$} & \multicolumn{12}{|c|}{ Bacterial strains } \\
\hline & & \multicolumn{2}{|c|}{$E f(+)$} & \multicolumn{2}{|c|}{$S a(+)$} & \multicolumn{2}{|c|}{$M R S A(+)$} & \multicolumn{2}{|c|}{$E c(-)$} & \multicolumn{2}{|c|}{$K p(-)$} & \multicolumn{2}{|c|}{$P a(-)$} \\
\hline & & MIC & $\mathrm{MBC}$ & MIC & MBC & MIC & MBC & MIC & MBC & MIC & MBC & MIC & MBC \\
\hline \multicolumn{14}{|l|}{ Elapidae } \\
\hline $\begin{array}{l}\text { Acanthophis } \\
\text { praelongus }\end{array}$ & $\begin{array}{c}\text { Northern } \\
\text { death adder }\end{array}$ & ND & ND & 2000 & 2000 & 4000 & 4000 & ND & ND & 4000 & 4000 & ND & ND \\
\hline $\begin{array}{l}\text { Dendroaspis } \\
\text { angusticeps }\end{array}$ & $\begin{array}{c}\text { Eastern green } \\
\text { mamba }\end{array}$ & ND & ND & ND & ND & ND & ND & ND & ND & ND & ND & ND & ND \\
\hline Naja atra & $\begin{array}{c}\begin{array}{c}\text { Chinese } \\
\text { cobra }\end{array} \\
\end{array}$ & ND & ND & 2000 & 2000 & 2000 & 2000 & ND & ND & 2000 & 2000 & ND & ND \\
\hline Naja kaouthia & $\begin{array}{c}\text { Monocled } \\
\text { cobra }\end{array}$ & ND & ND & 2000 & 2000 & 2000 & 2000 & ND & ND & 2000 & 2000 & ND & ND \\
\hline \multicolumn{14}{|l|}{ Viperidae } \\
\hline $\begin{array}{l}\text { Agkistrodon } \\
\text { piscivorus } \\
\text { leucostoma }\end{array}$ & $\begin{array}{l}\text { Western } \\
\text { cottonmouth }\end{array}$ & ND & ND & 125 & 125 & 125 & 125 & ND & ND & 62.5 & 62.5 & 4000 & 4000 \\
\hline $\begin{array}{l}\text { Agkistrodon } \\
\text { piscivorus } \\
\text { piscivorus }\end{array}$ & $\begin{array}{c}\text { Eastern } \\
\text { cottonmouth }\end{array}$ & ND & ND & 125 & 125 & 125 & 125 & ND & ND & 125 & 125 & 4000 & 4000 \\
\hline Bitis gabonica & Gaboon viper & ND & ND & 500 & 500 & 500 & 500 & ND & ND & 250 & 250 & ND & ND \\
\hline Crotalus atrox & $\begin{array}{c}\text { Western } \\
\text { diamondback } \\
\text { rattlesnake }\end{array}$ & ND & ND & 125 & 125 & 125 & 125 & ND & ND & 125 & 125 & ND & ND \\
\hline $\begin{array}{l}\text { Crotalus } \\
\text { polystictus }\end{array}$ & $\begin{array}{l}\text { Mexican } \\
\text { lance-headed } \\
\text { rattlesnake }\end{array}$ & ND & ND & 500 & 500 & 500 & 500 & ND & ND & 500 & 500 & ND & ND \\
\hline Daboia siamensis & $\begin{array}{c}\text { Eastern } \\
\text { Russell's } \\
\text { viper }\end{array}$ & ND & ND & 62.5 & 62.5 & 125 & 125 & ND & ND & 250 & 250 & ND & ND \\
\hline $\begin{array}{l}\text { Vipera latastei } \\
\text { gaditana }\end{array}$ & $\begin{array}{l}\text { Lataste's } \\
\text { viper }\end{array}$ & ND & ND & ND & ND & ND & ND & ND & ND & ND & ND & ND & ND \\
\hline
\end{tabular}

MIC - minimum inhibitory concentration $(\mu \mathrm{g} / \mathrm{mL})$; $\mathrm{MBC}-$ minimum bactericidal concentration $(\mu \mathrm{g} / \mathrm{mL})$;

ND - No antibacterial activity detected in the concentration range used.

for Elapidae and Viperidae snake venoms, under identical conditions. The obtained gels were used for protein blotting on a PVDF membrane and the bands were visualised using Ponceau $\mathrm{S}$ stain. The venoms obtained from species of the Viperidae family showed a higher diversity of proteinaceous fractions than those obtained from species of the Elapidae family. The digital images of the stained membranes are presented in Figure 3.

\section{Discussions}

The aim of our study was to correlate the qualitative composition of 11 different snake venoms (as determined by SDS-PAGE analysis and correlation of our findings with literature data) and their antibacterial activity, as observed on six different pathogenic bacterial strains. The 11 venoms were selected from two snake families: Elapidae (four species) and Viperidae (seven species). The geographical distribution of the 

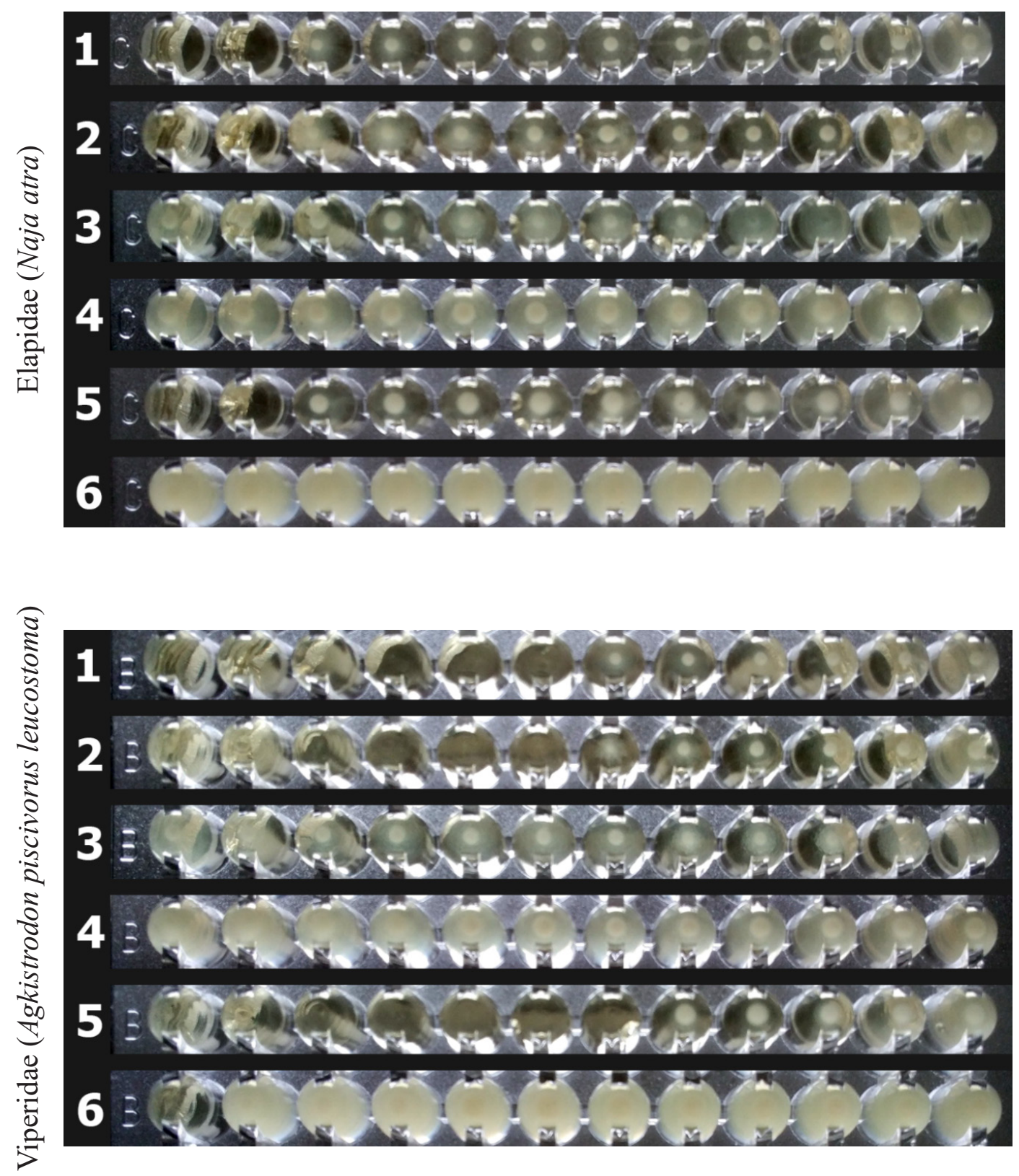

Fig. 1. Representative images (composed) showing the effects of Naja atra and Agkistrodon piscivorus leucostoma venoms on the tested bacteria: 1. Staphylococcus aureus; 2 . Methicillin-resistant Staphylococcus aureus; 3. Enterococcus faecalis; 4. Escherichia coli; 5. Klebsiella pneumoniae; 6. Pseudomonas aeruginosa. 


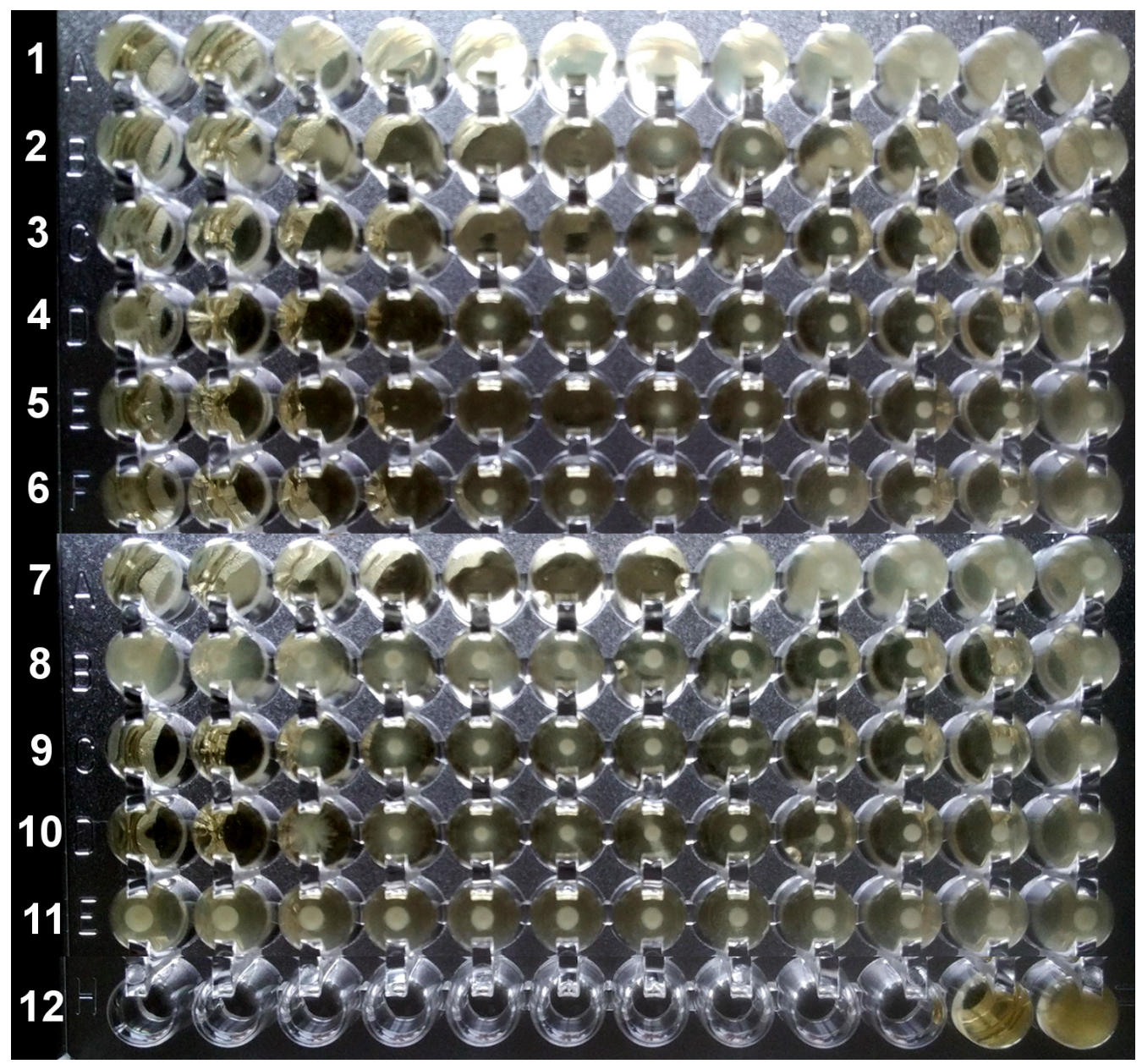

Fig. 2. Representative image showing the effect of the tested snake venoms on Staphylococcus aureus.

1. Acanthophis praelongus; 2. Agkistrodon piscivorus leucostoma; 3. Agkistrodon piscivorus piscivorus; 4. Bitis gabonica; 5. Crotalus atrox; 6. Crotalus polystictus; 7. Daboia siamensis; 8. Dendroaspis angusticeps; 9. Naja atra; 10. Naja kaouthia; 11. Vipera latastei gaditana; 12. Negative and positive controls.

selected species is as follow: Africa (B. gaboni$c a, D$. angusticeps), Southern and South-eastern Asia (A. praelongus, D. siamensis, $N$. atra, $N$. kaouthia), Central and North America (A. piscivorus leucostoma, $A$. piscivorus piscivorus, $C$. atrox, C. polystictus) and Southwestern Europe (V. latastei gaditana) (31).

In elapid venoms, smaller molecular weight toxins predominate, while viperid venoms are generally more abundant in higher-mass proteins. There is also a clear distinction in the complexity of venoms from the two snake families. Elapidae snake venoms are far simpler in their composition compared with Viperidae venoms. Using the SDSPAGE conditions employed, Elapidae venoms showed only 2 or 3 strong bands below $30 \mathrm{kDa}$, while Viperidae venoms showed complex patterns under $70 \mathrm{kDa}$.

A literature survey revealed that Elapidae venoms are usually abundant in low molecular mass 

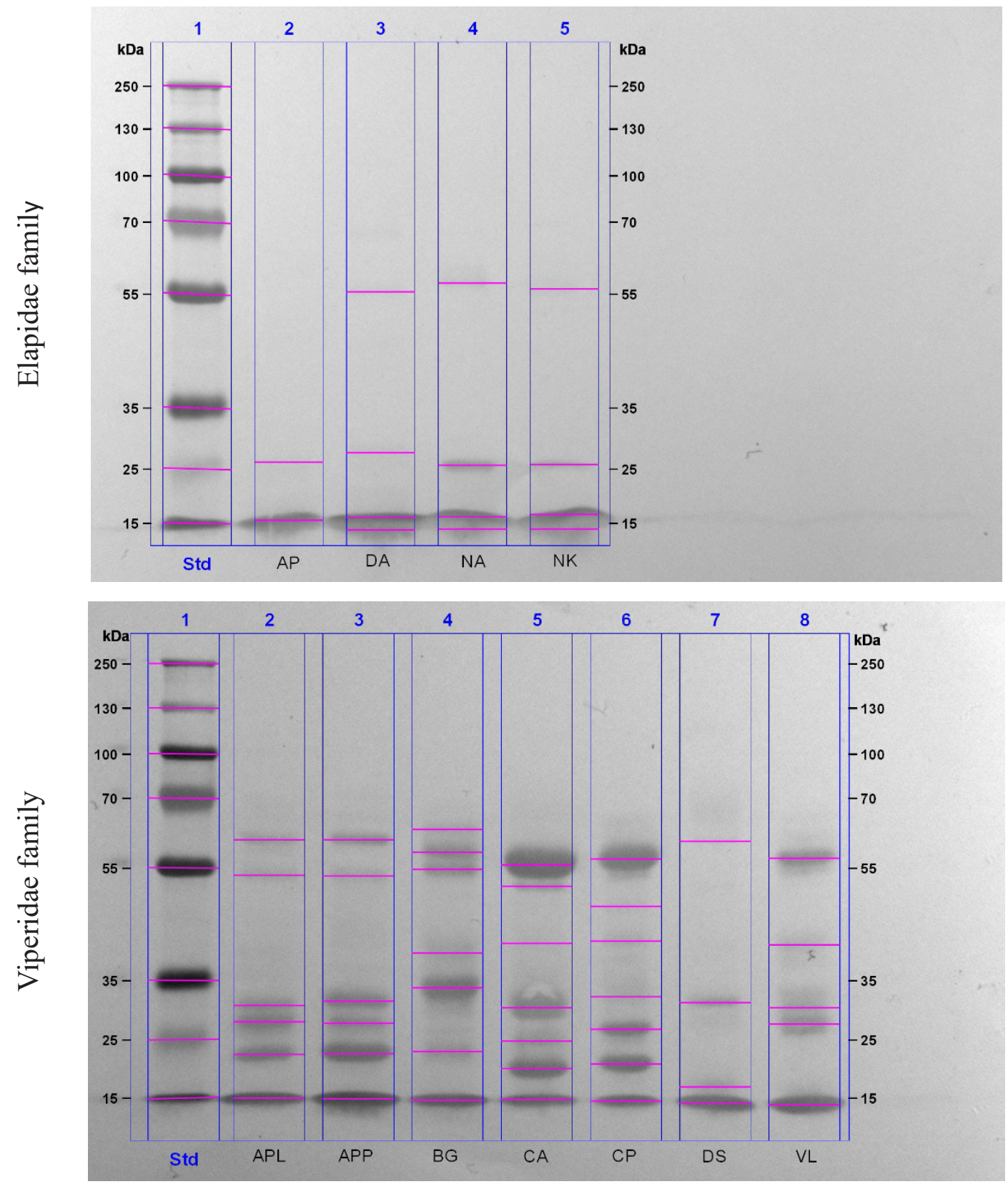

Fig. 3. Stained membranes following protein blotting of SDS-PAGE gels. Lanes and bands were identified using the automatic recognition function of the Image Lab Software version 5.2.1 (Bio-Rad Laboratories, USA), with manual adjustments if deemed necessary. (AP - Acanthophis praelongus; DA - Dendroaspis angusticeps; NA - Naja atra; NK - Naja kaouthia; APL - Agkistrodon piscivorus leucostoma; APP - Agkistrodon piscivorus piscivorus; BG - Bitis gabonica; CA - Crotalus atrox; CP - Crotalus polystictus; DS - Daboia siamensis; VL - Vipera latastei gaditana; Std - Thermo Scientific Pageruler Plus prestained protein ladder). 
three-finger neurotoxins (approximately 6-9 $\mathrm{kDa}$ ) and phospholipases $\mathrm{A}_{2}(13-15 \mathrm{kDa})$. In our study, intense bands appeared at around $15 \mathrm{kDa}$ for all Elapidae venoms tested, which probably correspond to the phospholipases $\mathrm{A}_{2}$, as this class of proteins was clearly identified in these venoms in earlier studies (32-35). Unfortunately, the SDS-PAGE conditions used did not offer a better resolution at lower molecular mass, thus, for example, three finger neurotoxins could not be retained on the gel.

Another clearly distinguishable band identified in the SDS-PAGE gels of elapid venoms was at around $25 \mathrm{kDa}$, which, based on literature data, corresponds to the family of cysteine-rich secretory proteins (CRISPs). These single-chain polypeptides were described in the secretions of numerous mammalian exocrine glands and also several snake species, including Naja kaouthia (36,37).

SDS-PAGE lanes corresponding to Dendroaspis angusticeps, Naja atra, and Naja kaouthia also contained weak bands at around $55 \mathrm{kDa}$, which could be attributed to SVMPs and sv-LAAOs. Although present in Elapidae venoms, these enzymes usually amount to only a small percentage of their total protein content. For example, Tan et al. found that in venoms of Naja kaouthia from different geographical regions of Asia sv-LAAOs represented only around $1 \%$, while SVMPs amounted to $2-3 \%$ of all proteins identified (35).

The obtained SDS-PAGE gels suggested that the protein profile of the analysed Elapidae venoms was simple and showed a high similarity between the tested species. The obtained data suggested the lack of peptides with specific antibacterial activity, which is in line with the high MIC and MBC values obtained for these venoms. Furthermore, the homogeneity of the venom composition of the tested elapid species was in line with the similar MIC and MBC values obtained for these venoms.
The tested viperid venoms showed a much more complex protein profile and heterogeneity between species, demonstrated both by the variation in the obtained MIC and MBC values and the SDS-PAGE profiles of these venoms.

Viperid venoms displayed a strong, seemingly homogenous band at approximately $15 \mathrm{kDa}$, which are usually associated with sv-PLA 2 s. As opposed to elapid venoms, higher-molecular weight components predominate in viperid venoms. Hydrolytic enzymes, especially serine proteases, are observable between 25 and $35 \mathrm{kDa}$, which were absent in the tested elapid venoms (38). SVMPs are also expected to be abundant in viperid venoms, with P-I class SVMPs visible at approximately $20-30 \mathrm{kDa}, \mathrm{P}$-II class visible at 30-60 kDa, and P-III class visible above $60 \mathrm{kDa}$ (25). P-I class and P-II class SVMPs were identified on the SDS-PAGE gels as strong bands in the venom of both Crotalus species at around 21 $\mathrm{kDa}$ and $55 \mathrm{kDa}$, respectively. This finding is in line with literature data, which suggest a high abundance of SVMPs in Crotalus venoms (39). Although the SDS-PAGE lanes were similar, differences were found in the antibacterial activity of the Crotalus venoms tested, the venom obtained from Crotalus atrox expressing a higher activity than that from Crotalus polystictus on susceptible strains.

Interestingly, the venom obtained from Daboia siamensis displayed the highest antibacterial activity against Gram-positive species ( $S$. aureus and MRSA), although its SDS PAGE analysis revealed a very simple composition when compared with other viperid venoms. Daboia siamensis venom also displayed a relatively high activity against Gram-negative $K$. pneumoniae. The highly expressed sv-PLA 2 is the most probable contributor for its antibacterial effect on Gram-positive bacteria. It was found that the bacterial sensitivity to phospholipases $\mathrm{A}_{2}$ is highly variable, but generally, Gram-positive bacteria are susceptible, as these enzymes quickly 
penetrate and damage the bacterial phospholipid bilayer. This is the reason why most venoms showed a good antibacterial effect on Gram-positive bacteria. Within this group, enterococci and streptococci were found to be more resistant than staphylococci, probably due to their ability to replace the degraded phospholipids of the cytoplasmic membrane (40), or due to the possible presence of aggregation substances in enterococci, which makes them spontaneously clump (41). The asymmetrical distribution of lipopolysaccharides in Gram-negative bacteria limits the access of $\mathrm{PLA}_{2} \mathrm{~s}$ to the phospholipid bilayer of the cytoplasmic membrane, providing resistance to phospholipases (40). Furthermore, many Gram-negative bacteria express phospholipase activity, thus making them naturally unresponsive to this class of enzymes (42). The ExuU gene of many Pseudomonas species encodes a bacterial phospholipase $A_{2}$, which provides the specific phospholipase activity (43). Outer membrane phospholipases have also been described for several other Gram-negative bacteria (42). The highly active proteolytic equipment of $P$. aeruginosa may also explain the high resistance of this bacterial species against the tested venoms. The different response of Gram-negative bacteria to the tested venoms, especially the sensitivity of $K$. pneumoniae may be attributed to the variation of carbohydrate binding specificity of the venom components or to the structural diversity of the bacterial glycoconjugates (44).

The two Agkistrodon venoms tested showed similarities between their SDS-PAGE profiles and similar antibacterial characteristics. The only difference was found for $K$. pneumoniae susceptibility, where $A$. piscivorus leucostoma displayed lower MIC and MBC values than $A$. piscivorus piscivorus. The venoms obtained from the two Agkistrodon species were also the only venoms showing antibacterial activity against $P$. aeruginosa. Based on the obtained SDS PAGE gels and literature data (45), the following pro- tein families were identified: sv $\mathrm{PLA}_{2} \mathrm{~s}$ and/or galactoside-binding lectins $(\sim 15 \mathrm{kDa})$, P-I class SVMPs $(\sim 22 \mathrm{kDa})$, serine proteases $(\sim 28-30$ $\mathrm{kDa})$, P-II class SVMPs $(\sim 54 \mathrm{kDa})$, and P-III class SVMPs $(\sim 62 \mathrm{kDa})$.

The venom obtained from Bitis gabonica showed moderate antibacterial activity, compared with other viperid venoms with an MIC and MBC on susceptible strains of $250-500 \mu \mathrm{g} / \mathrm{mL}$. Based on literature data, the bands observed on our SDS-PAGE correspond to PLA $2 \mathrm{~s}(\sim 15 \mathrm{kDa})$, serine proteases $(\sim 34 \mathrm{kDa})$, and SVMPs (P-I class at $\sim 23 \mathrm{kDa}, \mathrm{P}$-II class at $\sim 55 \mathrm{kDa}$ and P-III class above $60 \mathrm{kDa}$ ).

Interestingly, no antibacterial activity could be observed for Vipera latastei gaditana venom at a concentration of $4000 \mu \mathrm{g} / \mathrm{mL}$, although its composition showed similarities to other tested viperid venoms. A possible explanation for the lack of activity of this venom could be that the $15 \mathrm{kDa}$ fragment corresponds to a lectin with low antibacterial effect $(46,47)$, rather than to sv $\mathrm{PLA}_{2} \mathrm{~s}$. The missing protein fractions in the range of $15-25 \mathrm{kDa}$ in the lane corresponding to $V$. latastei gaditana venom may further indicate

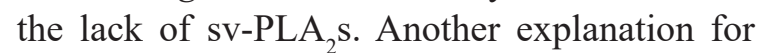
the lack of antibacterial effect of $V$. latastei $g a$ ditana venom could be that the protein components found in the venom do not possess significant proteolytic activity required to disrupt the bacterial membrane.

\section{Conclusions}

The antibacterial activity testing showed a marked difference between venoms originating from elapid and viperid species, with the venoms from viperid species having a significantly higher antibacterial activity, probably due to their content in proteins with proteolytic activity. Based on the obtained protein profile, the most likely components responsible for the antibacterial activity are phospholipases $\mathrm{A}_{2}$ and metal- 
loproteinases. Inter-species variation in the antibacterial activity could also be observed, likely caused by differences in the proteolytic activity of the proteins contained in the venoms.

The screening of snake venoms for antibacterial activity showed that the most potent venom was that of Daboia siamensis, along with the venom from the two Agkistrodon species. The venoms obtained from Agkistrodon species not only showed low MIC and MBC values for susceptible species, but were the only venoms exerting antibacterial activity on $P$. aeruginosa. Fractionation and isolation of individual venom components from these species, along with the screening of their antibacterial activity could lead to the identification of new lead molecules for the development of antibacterial agents.

\section{Authors' contribution}

Francisc Andrei Boda (Resources; Writing original draft)

Anca Mare (Investigation; Methodology)

Zoltán István Szabó (Writing - original draft)

Lavinia Berta (Formal analysis; Validation)

Augustin Curticapean (Data curation; Visualization)

Maria Dogaru (Conceptualization; Supervision) Adrian Man (Methodology; Writing - review \& editing)

\section{Acknowledgements}

The first author was supported by the Collegium Talentum 2018 Programme of Hungary.

The authors declare no conflict of interest.

\section{Abbreviations}

CRISP - cysteine-rich secretory protein

$\mathrm{MBC}$ - minimum bactericidal concentration

MIC - minimum inhibitory concentration

MRSA - methicillin-resistant Staphylococcus aureus

SDS-PAGE - sodium dodecyl sulphate - poly- acrylamide gel electrophoresis

SV-LAAO - snake venom L-amino acid oxidase SVMP - snake venom metalloproteinase sv-PLA $A_{2}$ - snake venom phospholipase $\mathrm{A}_{2}$

\section{References}

1. Laxminarayan R, Duse A, Wattal C, Zaidi AKM, Wertheim HFL, Sumpradit N, et al. Antibiotic resistance-the need for global solutions. Lancet Infect Dis. 2013;13(12):1057-98. DOI: 10.1016/S14733099(13)70318-9

2. Exner M, Bhattacharya S, Christiansen B, Gebel J, Goroncy-Bermes P, Hartemann P, et al. Antibiotic resistance: What is so special about multidrug-resistant Gram-negative bacteria? GMS Hyg Infect Control. 2017;12:Doc05.

3. Munteanu F, Gligor R, Cricirc;snic I, Costache CA, Colosi IA. Antimicrobial activity of Melampyrum cristatum, Melampyrum bihariense and Melampyrum arvense tinctures. African J Pharm Pharmacol. Academic Journals; 2012 Oct 31;6(40):2808-12.

4. Tănase C, Coşarcă S, Toma F, Mare A, Man A, Miklos A, et al. Antibacterial activities of beech bark (Fagus sylvatica L.) polyphenolic extract. Environ Eng Manag J. 2018;17(4):877-84. DOI: 10.30638/eemj.2018.088

5. Man A, Santacroce L, Jacob R, Mare A, Man L. Antimicrobial Activity of Six Essential Oils Against a Group of Human Pathogens: A Comparative Study. Pathogens. 2019 Jan 28;8(1):15. DOI: 10.3390/pathogens8010015

6. Han SM, Kim JM, Hong IP, Woo SO, Kim SG, Jang $\mathrm{HR}$, et al. Antibacterial activity and antibiotic-enhancing effects of honeybee venom against methicillin-resistant staphylococcus aureus. Molecules. 2016; DOI: 10.3390/molecules21010079

7. Dubovskii P V., Ignatova AA, Volynsky PE, Ivanov IA, Zhmak MN, Feofanov A V., et al. Improving therapeutic potential of antibacterial spider venom peptides: coarse-grain molecular dynamics guided approach. Future Med Chem. 2018 Oct 1;10(19):2309-22. DOI: 10.4155/fmc-2018-0170

8. de Oliveira Junior NG, e Silva Cardoso MH, Franco OL. Snake venoms: Attractive antimicrobial proteinaceous compounds for therapeutic purposes. Cell Mol Life Sci. 2013;70(24):4645-58. DOI: 10.1007/s00018013-1345-x

9. Harvey AL. Toxins and drug discovery. Toxicon. 2014;92:193-200. DOI: 10.1016/j.toxicon.2014.10.020

10. Koh CY, Kini RM. From snake venom toxins to therapeutics - Cardiovascular examples. Toxicon. 2012;59(4):497-506. DOI: 10.1016/j.toxicon.2011.03.017

11. Pennington MW, Czerwinski A, Norton RS. Peptide therapeutics from venom: Current status and potential. Bioorganic Med Chem. 2018 Jun 1;26(10):2738-58. 
DOI: 10.1016/j.bmc.2017.09.029

12. McCleary RJR, Kini RM. Snake bites and hemostasis/thrombosis. Thromb Res. 2013;132:642-6. DOI: 10.1016/j.thromres.2013.09.031

13. Waheed H, Moin SF, Choudhary MI. Snake Venom: From Deadly Toxins to Life-saving Therapeutics. Curr Med Chem. 2017;24(17):1874-91. DOI: 10.2174/0929 867324666170605091546

14. Calderon LA, Sobrinho JC, Zaqueo KD, De Moura AA, Grabner AN, Mazzi MV., et al. Antitumoral activity of snake venom proteins: New trends in cancer therapy. Biomed Res Int. 2014;2014:1-19. DOI: $10.1155 / 2014 / 203639$

15. Shanbhag VKL. Applications of snake venoms in treatment of cancer.Asian Pac JTrop Biomed. 2015;5(4):2756. DOI: 10.1016/S2221-1691(15)30344-0

16. Gazerani P, Cairns BE. Venom-based biotoxins as potentialanalgesics.ExpertRevNeurother.2014;14(11):126174. DOI: $10.1586 / 14737175.2014 .962518$

17. Stiles BG, Sexton FW, Weinstein SA. Antibacterial effects of different snake venoms: Purification and characterization of antibacterial proteins from Pseudechis australis (Australian king brown or mulga snake) venom. Toxicon. 1991;29(9):1129-41. DOI: 10.1016/0041-0101(91)90210-I

18. Talan DA, Citron DM, Overturf GD, Singer B, Froman P, Goldstein EJC. Antibacterial activity of crotalid venoms against oral snake flora and other clinical bacteria. J Infect Dis. 1991;164(1):195-8. DOI: 10.1093/ infdis/164.1.195

19. Samy RP, Gopalakrishnakone P, Thwin MM, Chow TKV, Bow H, Yap EH, et al. Antibacterial activity of snake, scorpion and bee venoms: A comparison with purified venom phospholipase A2 enzymes. J Appl Microbiol. 2007;102(3):650-9. DOI: 10.1111/j.13652672.2006.03161.x

20. Montecucco C, Gutiérrez JM, Lomonte B. Cellular pathology induced by snake venom phospholipase A2 myotoxins and neurotoxins: Common aspects of their mechanisms of action. Cell Mol Life Sci. 2008;65(18):2897-912. DOI: 10.1007/s00018-0088113-3

21. Gutiérrez JM, Lomonte B. Phospholipases A2: Unveiling the secrets of a functionally versatile group of snake venom toxins. Toxicon. 2013;62:27-39. DOI: 10.1016/j.toxicon.2012.09.006

22. Rodrigues RS, Izidoro LFM, de Oliveira RJ, Sampaio S V, Soares AM, Rodrigues VM. Snake venom phospholipases A2: a new class of antitumor agents. Protein Pept Lett. 2009;16(8):894-8. DOI: 10.2174/092986609788923266

23. Samy RP, Gopalakrishnakone P, Stiles BG, Girish KS, Swamy SN, Hemshekhar M, et al. Snake venom phospholipases A(2): a novel tool against bacterial diseases. Curr Med Chem. 2012;19(36):6150-62. DOI:
10.2174/0929867311209066150

24. Xu C, Ma D, Yu H, Li Z, Liang J, Lin G, et al. A bactericidal homodimeric phospholipases $\mathrm{A} 2$ from Bungarus fasciatus venom. Peptides. 2007;28(5):969-73. DOI: 10.1016/j.peptides.2007.02.008

25. Markland FS, Swenson S. Snake venom metalloproteinases. Toxicon. 2013;62:3-18. DOI: 10.1016/j.toxicon.2012.09.004

26. Samy RP, Gopalakrishnakone P, Chow VTK, Ho B. Viper metalloproteinase (Agkistrodon halys Pallas) with antimicrobial activity against multi-drug resistant human pathogens. J Cell Physiol. 2008;216(1):54-68. DOI: $10.1002 /$ jep. 21373

27. Izidoro LFM, Sobrinho JC, Mendes MM, Costa TR, Grabner AN, Rodrigues VM, et al. Snake venom L-amino acid oxidases: Trends in pharmacology and biochemistry. Biomed Res Int. 2014;2014:1-19. DOI: $10.1155 / 2014 / 196754$

28. Zhang H, Yang Q, Sun M, Teng M, Niu L. Hydrogen peroxide produced by two amino acid oxidases mediates antibacterial actions. J Microbiol. 2004;42(4):3369.

29. CLSI. Methods for Dilution Antimicrobial Susceptibility Tests for Bacteria That Grow Aerobically. Approved Standard-Tenth Edition. CLSI document M07-A10. 2015. 1-87 p.

30. Laemmli UK. Cleavage of structural proteins during the assembly of the head of bacteriophage T4. Nature. 1970;227(5259):680-5. DOI: 10.1038/227680a0

31. The Reptile Database [Internet]. [cited 2019 Jan 28]. Available from: http://www.reptile-database.org/

32. Fry BG, Wickramaratna JC, Hodgson WC, Alewood PF, Kini RM, Ho H, et al. Electrospray liquid chromatography/mass spectrometry fingerprinting of Acanthophis (death adder) venoms: Taxonomic and toxinological implications. Rapid Commun Mass Spectrom. 2002;16:600-8. DOI: 10.1002/rcm.613

33. Petras D, Heiss P, Harrison RA, Süssmuth RD, Calvete JJ. Top-down venomics of the East African green mamba, Dendroaspis angusticeps, and the black mamba, Dendroaspis polylepis, highlight the complexity of their toxin arsenals. J Proteomics. 2016;146:148-64. DOI: $10.1016 /$ j.jprot.2016.06.018

34. Huang HW, Liu BS, Chien KY, Chiang LC, Huang SY, Sung WC, et al. Cobra venom proteome and glycome determined from individual snakes of Naja atra reveal medically important dynamic range and systematic geographic variation. J Proteomics. 2015;128:92-104. DOI: 10.1016/j.jprot.2015.07.015

35. Tan KY, Tan CH, Fung SY, Tan NH. Venomics, lethality and neutralization of Naja kaouthia (monocled cobra) venoms from three different geographical regions of Southeast Asia. J Proteomics. 2015;120:105-25. DOI: 10.1016/j.jprot.2015.02.012

36. Osipov A V., Levashov MY, Tsetlin VI, Utkin YN. 
Cobra venom contains a pool of cysteine-rich secretory proteins. Biochem Biophys Res Commun. 2005;328:177-82. DOI: 10.1016/j.bbrc.2004.12.154

37. Modahl CM, Mukherjee AK, Mackessy SP. An analysis of venom ontogeny and prey-specific toxicity in the Monocled Cobra (Naja kaouthia). Toxicon. 2016;119:8-20. DOI: 10.1016/j.toxicon.2016.04.049

38. Serrano SMT. The long road of research on snake venom serine proteinases. Toxicon. 2013;62:19-26. DOI: 10.1016/j.toxicon.2012.09.003

39. Calvete JJ, Fasoli E, Sanz L, Boschetti E, Righetti PG. Exploring the venom proteome of the western diamondback rattlesnake, Crotalus atrox, via snake venomics and combinatorial peptide ligand library approaches. J Proteome Res. 2009;8:3055-67. DOI: $10.1021 /$ pr900249q

40. Weiss JP. Molecular determinants of bacterial sensitivity and resistance to mammalian Group IIA phospholipase A2. Biochim Biophys Acta - Biomembr. 2015;1848:3072-7. DOI: 10.1016/j.bbamem.2015.05.018

41. Sartingen S, Rozdzinski E, Muscholl-Silberhorn A, Marre R. Aggregation substance increases adherence and internalization, but not translocation, of Enterococcus faecalis through different intestinal epithelial cells in vitro. Infect Immun. 2000 Oct;68(10):6044-7. DOI: 10.1128/IAI.68.10.6044-6047.2000
42. Istivan TS, Coloe PJ. Phospholipase A in Gram-negative bacteria and its role in pathogenesis. Microbiology. 2006;152:1263-74. DOI: 10.1099/mic.0.28609-0

43. Klockgether J, Tümmler B. Recent advances in understanding Pseudomonas aeruginosa as a pathogen. F1000Research. 2017;6(1261):1-10. DOI: 10.12688/ f1000research.10506.1

44. Tytgat HLP, Lebeer S. The Sweet Tooth of Bacteria: Common Themes in Bacterial Glycoconjugates. Microbiol Mol Biol Rev. 2014;78(3):372-417. DOI: 10.1128/ MMBR.00007-14

45. Lomonte B, Tsai WC, Ure-a-Diaz JM, Sanz L, Mora-Obando D, Sánchez EE, et al. Venomics of new world pit vipers: Genus-wide comparisons of venom proteomes across agkistrodon. J Proteomics. 2014;96:103-16. DOI: 10.1016/j.jprot.2013.10.036

46. Nunes E dos S, de Souza MAA, Vaz AF de M, Santana GM de S, Gomes FS, Coelho LCBB, et al. Purification of a lectin with antibacterial activity from Bothrops leucurus snake venom. Comp Biochem Physiol - B Biochem Mol Biol. 2011;159:57-63. DOI: 10.1016/j. cbpb.2011.02.001

47. Sartim MA, Sampaio S V. Snake venom galactoside-binding lectins: A structural and functional overview. J Venom Anim Toxins Incl Trop Dis. 2015;21(35):1-11. DOI: 10.1186/s40409-015-0038-3 